\title{
Olfactory deficit as a result of clozapine withdrawal syndrome in an animal model of schizophrenia: preliminary results
}

\author{
FELIPE D. PACHECO, MAURICIO L. DA SILVA, GRAZIELA BATISTA, WITÓRIA SANTOS, \\ ADALBERTO A. DE CASTRO, LARA CANEVER and ALEXANDRA I. ZUGNO \\ Programa de Pós-Graduação em Ciências da Saúde, Universidade do Extremo Sul Catarinense, \\ Unidade Acadêmica de Ciências da Saúde, Laboratório de Neurociências, Av. Universitária, \\ 1105, Bloco S, Sala 5/ subsolo, Universitário, 88806-000 Criciúma, SC, Brazil
}

Manuscript received on July 3, 2017; accepted for publication on November 7, 2017

\begin{abstract}
Clozapine is an antipsychotic that produces serious withdrawal effects in schizophrenic patients. Olfactory deficits are well known as part of negative symptoms, but it is not known whether antipsychotic use and/or withdrawal are implicated. Then, we tested clozapine withdrawal in association with two widely used schizophrenia models: Neonatal immune challenge by Polycitidilic-polyinosinic acid (polyI:C) and ketamine. PolyI:C (or saline) was injected subcutaneously in neonatal period, dose of $5 \mathrm{mg} / \mathrm{kg}$ from 2 to 6 Post Natal Days, and ketamine or saline at the dose $25 \mathrm{mg} / \mathrm{kg}$ intraperitoneally (i.p.), daily for 7 days from 53 to 60 post natal day. Clozapine $10 \mathrm{mg} / \mathrm{kg}$ (or saline) was administered i.p. from 46 to 60 post natal day. Olfactory discrimination test (sensorial and cognitive deficit) was performed at 61 post natal day, 24h after the last injections. The association of PolyI:C, ketamine and clozapine disrupted Olfactory Discrimination, equating time in familiar and non-familiar compartments. PolyI:C plus ketamine increased crossings between compartments. It was produced, for the first time, an olfactory deficit induced by clozapine withdrawal in Wistar rats subjected to schizophrenia animal models.
\end{abstract}

Key words: Olfactory deficit, clozapine, schizophrenia, animal model.

\section{INTRODUCTION}

Clozapine is an antipsychotic that produces serious withdrawal effects in schizophrenic patients (Wadekar and Syed 2010, Yeh et al. 2004). Olfactory deficits are well known in schizophrenic patients, but it is unclear whether such deficits are due to the condition itself, or a side effect of long term antipsychotic use (Ansoleaga et al. 2015, Kiparizoska and Ikuta 2017). Regarding rodents,

Correspondence to: Alexandra Ioppi Zugno

E-mail: alz@unesc.net seeking for the nest's odour is also a social skill, pivotal for survival (Scheider and Przewłocki 2005, Miller and Spear 2009). It is well known that rodents prefer staying in "familiar" ambient, with odours of urine, faeces and feromones from other rodents of its social groups, and the odours of its own body (de Souza et al. 2012). The present study aims, therefore, to verify the role of olfactory deficit as a symptom of clozapine withdrawal in SZ, using two well established SZ models: (Hida et al. 2014): neonatal immune challenge with polyI:C 
(Pearce 2001) and N-methyl-D-aspartate receptor hypofunction by subanesthetic doses of ketamine (Zugno et al. 2016).

\section{MATERIALS AND METHODS}

\section{ANIMALS}

Male Wistar rats were obtained from colonies kept in the vivarium of Universidade do Extremo Sul Catarinense (UNESC). The present work was submitted to the Ethics Committee on Animal Experimentation of Universidade do Extremo Sul Catarinense (UNESC-CEUA), and approved by the protocol number 061 / 2013-2.

\section{DRUGS}

Polycitidilic-poly-inosinic acid (PolyIC, Tocris Biosciences) $5 \mathrm{mg} / \mathrm{kg}$ subcutaneously (or saline in the volume of $1 \mathrm{ml} / \mathrm{kg}$ ) from 2 to 6 PND (Hida et al. 2014).

Ketamine $25 \mathrm{mg} / \mathrm{kg}, 1 \mathrm{ml} / \mathrm{kg}$ (CUChemieUetikon, Germany), by intraperitoneal (i.p.) route, from 53 PND to 60 PND (Zugno et al. 2016).

Clozapine $10 \mathrm{mg} / \mathrm{kg}$ (Novartis, Switzerland) was administered i.p. between 46 and 60 PND, dissolved in acetic acid and diluted in saline in volume of $1 \mathrm{ml} / \mathrm{kg}$ (Chatterjee et al. 2011).

\section{EXPERIMENTAL DESIGN}

The experimental groups were:

1) Saline + saline + saline;

2) Saline+saline+ketamine;

3) Saline+saline+clozapine;

4) Saline+ketamine+clozapine;

5) PolyI:C+saline+saline;

6) PolyI:C+ketamine+saline;

7) PolyI:C+clozapine+saline;

8) PolyI:C+ketamine+clozapine.

The number of animals varied from 10 to 13 animals per group. This number varied because the administration of polyI:C (or saline) s.c. took place in the neonatal period, and it was not possible to separate the pups from their mothers, therefore, the number of subjects depended on the number of male rats born from each mother. The pups of each mother received the same treatment (polyI:C or saline), and only after 23 post natal days male rats were separated in the 8 experimental groups.

PolyI:C (or saline) was injected subcutaneously in neonatal period, dose of $5 \mathrm{mg} / \mathrm{kg}$ from 2 to 6 Post Natal Days, and ketamine or saline at the dose 25 $\mathrm{mg} / \mathrm{kg}$ intraperitoneally (i.p.), daily for 7 days from 53 to 60 post natal day. Clozapine $10 \mathrm{mg} / \mathrm{kg}$ (or saline) was administered i.p. from 46 to 60 post natal day.

Olfactory discrimination test (sensorial and cognitive deficit) was performed at 61 post natal day, $24 \mathrm{~h}$ after the last injections.

\section{OLFACTORY DISCRIMINATION TASK}

The present test was performed according to Castro et al. (2012). The animals, which were housed since the weaning 5 animals in each box, were transferred to an isolated box, in which they were kept for 3 days (from 1 day prior the last injections until the day of the task, $24 \mathrm{~h}$ after the last injections). This period of isolation was necessary to the rat, so it soaks the wood shavings of the box with its odours of faeces, urine, and pheromones. The task was performed in a wooden box divided in two compartments by a wall, having an entrance between the compartments. On the day of the task, the wood shavings of the isolated rat were poured in one of the compartments (familiar compartment), and the other compartment was filled with fresh wood shavings (non-familiar compartment). The animal was put in the familiar compartment, and its activity was monitored for 5 minutes. Time in seconds of permanence in the familiar and non-familiar compartment was measured, as well as the number of crossings between the compartments. The animal that had the time in familiar compartment statistically longer 
than in the time in the non-familiar compartment was considered to have normal OD. The animal that had the time in both compartments statistically equal was considered to have disrupted Olfactory Discrimination.

\section{NUMBER OF CROSSINGS BETWEEN COMPARTMENTS}

This measure had the aim to detect the degree of difficulty necessary for accomplishing the Olfactory Discrimination test (Castro et al. 2012).

\section{STATISTICS}

For time in the compartments in the Olfactory Discrimination test, we performed, after normality tests, Ratio paired t-tests within each treatment group (time in familiar compartment versus time in non-familiar compartment), and for the number of crossings, Two-Way ANOVA followed by Tukey post hoc test was performed. We utilized the software Graph Pad Prism 7.0 (GraphPad Software, La Jolla, Calif., USA).

\section{RESULTS}

For Olfactory Discrimination (Figure 1a), all the groups except for PolyI:C+Ketamine+Clozapine group fulfilled the task, spending more time in the familiar compartment than in the nonfamiliar compartment. Ratio paired t-test revealed $\mathrm{p}=0.0477$ for saline + saline + saline; $\mathrm{p}=0.0024$ for Saline + saline + ketamine; $\mathrm{p}=0.0043$ for Saline + saline + clozapine; $\mathrm{p}=0.001$ for Saline+ketamine + clozapine; $\mathrm{p}=0.0074$ for PolyI:C+saline + saline; $\mathrm{p}=0.0199$ for PolyI:C+saline+ketamine; $\mathrm{p}=0.0199$ for PolyI:C+saline+clozapine and $\mathrm{p}=0.6014$ for PolyI:C+ketamine+clozapine, meaning that rats of PolyI:C+ketamine+clozapine group had disrupted olfactory discrimination.

For Number of Crossings in the Discriminatory Olfaction test (Figure 1b), Two-way ANOVA revealed that PolyI:C had a main effect $[\mathrm{F}(1,97)$ $=13.87 ; \mathrm{p}=0.0003]$; but not ketamine and/or clozapine $[\mathrm{F}(3,97)=1.135 ; \mathrm{p}=0.3387]$ with no interaction either $[\mathrm{F}(3,97)=1.611 ; \mathrm{p}=0.1918]$. Post hoc test revealed that the PolyI:C+ketamine+saline group had increased number of crossings during the task.

\section{DISCUSSION}

Our results suggest that clozapine withdrawal produced a sensorial deficit, suggestive of abstinence of this drug, only in the group PolyI:C+ketamine+clozapine, which was subjected both to a perinatal immune challenge and ketamine treatment (Figure 1a). PolyI:C+ketamine+saline group also had increased number of crossings between the compartments without altering the normal time in familiar compartment, suggesting that the task was accomplished, but with more difficulty by PolyI:C+ketamine+saline group (Figure 1b). Since the task was performed $24 \mathrm{~h}$ after the last injections, and there is no evidence in previous literature of clozapine accumulation in the rat brain (Baldessarini et al. 1993), the effect in the olfactory discrimination in the PolyI:C+ketamine+clozapine group could only be mediated by alterations in the receptors which were subjected to clozapine action, mainly serotonergic, but also histaminergic, cholinergic, and others (Goudie et al. 1999), following the absence of the drug. The olfactory deficit in the present work represents a severe impairment of sensorial processes (Schneider and Przewłocki 2005, Niu et al. 2015). To our knowledge, olfactory deficits have not yet been tested in SZ patients in this specific situation (CLZ withdrawal). However, long term antipsychotic use has been associated with olfactory deficits in SZ, but it has been impossible to establish a causal relation (Ansoleaga et al. 2015, Kiparizoska and Ikuta 2017). Then, our study 


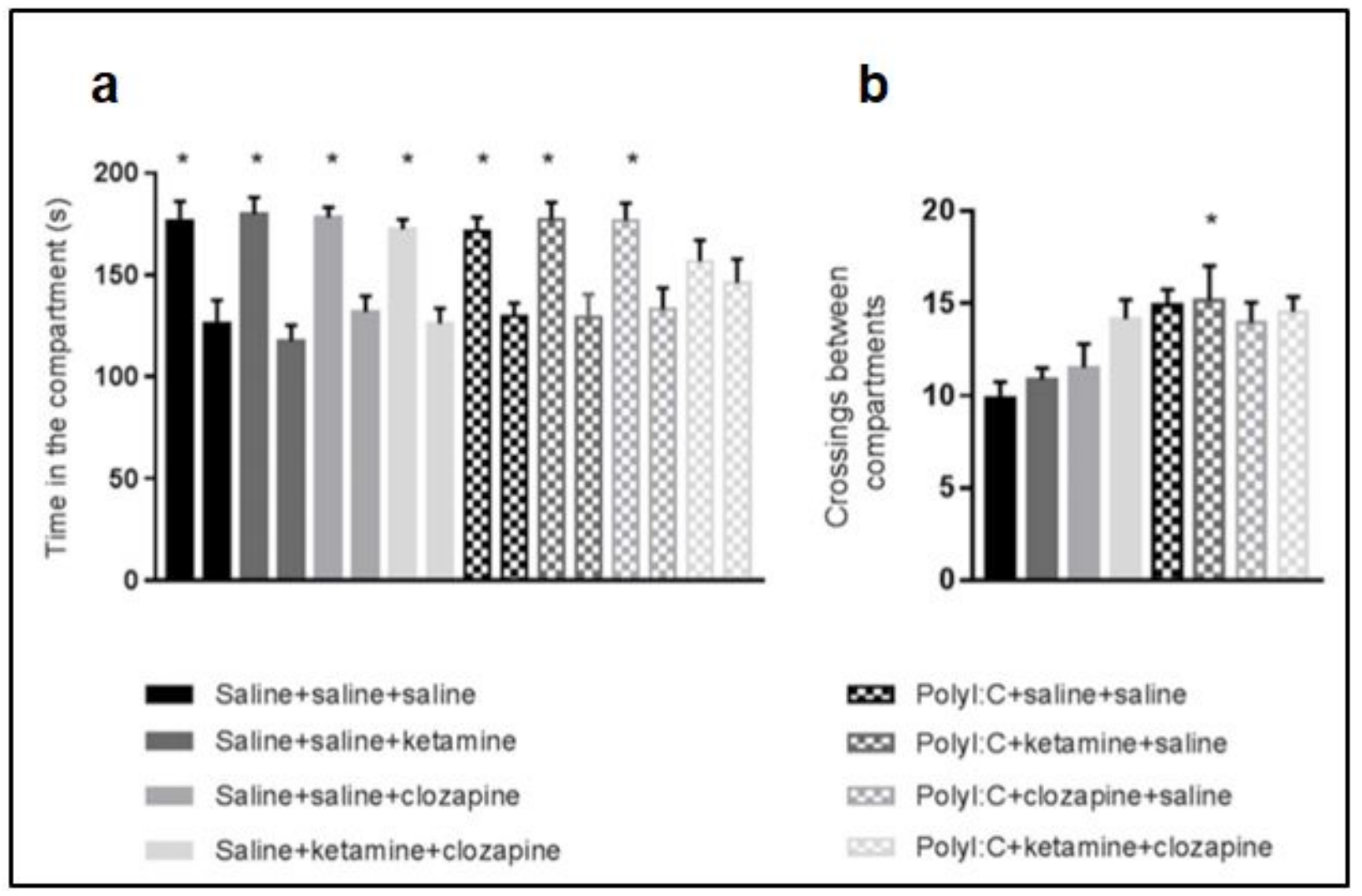

Figure 1 - Results for Olfactory Discrimination: time (in seconds) in familiar and non-familiar compartments (a) and number of crossings between the compartments (b). Results expressed in mean +/- Standard Error of the Mean (S.E.M). *statistically significant difference, $\mathrm{p}<0.05$, among the time in compartments (a) and in comparision with Saline + saline + saline group (b).

raises the hypothesis that OD deficits in SZ may be linked with antipsychotics' withdrawal.

\section{ACKNOWLEDGMENTS}

The authors thank the Conselho Nacional de Desenvolvimento Cientifico e Tecnológico (CNPq) and Fundação de Amparo à Pesquisa e Inovação do Estado de Santa Catarina (FAPESC), agencies responsible for economic aid.

\section{REFERENCES}

ANSOLEAGA B, GARCIA-ESPARCIA P, PINACHO R, HARO JM, RAMOS B AND FERRER I. 2015. Decrease in olfactory and taste receptor expression in the dorsolateral prefrontal cortex in chronic schizophrenia. J Psychiatr Res 60: 109-116.

BALDESSARINI RJ, CENTORRINO F, FLOOD JG, VOLPICELLI SA, HUSTON-LYONS D AND COHEN
BM. 1993. Tissue concentrations of clozapine and its metabolites in the rat. Neuropsychopharmacology 9(2): 117-124.

CASTRO AA, GHISONO K, LATINI A, QUEVEDO J, TASCA CI AND PREDIGER RD. 2012. Lithium and valproate prevent olfactory discrimination and shortterm memory impairments in the intranasal 1-methyl-4phenyl-1,2,3,6-tetrahydropyridine (MPTP) rat model of Parkinson's disease. Behav Brain Res 229(1): 208-215.

CHATTERJEE M, GANGULY S, SRIVASTAVA M AND PALIT G. 2011. Effect of 'chronic' versus 'acute' ketamine administration and its 'withdrawal' effect on behavioural alterations in mice: implications for experimental psychosis. Behav Brain Res 216(1): 247-254.

DE SOUZA MA, SZAWKA RE, CENTENARO LA, DIEHL LAAND LUCION AB. 2012. Prenatal stress produces sex differences in nest odor preference. Physiol Behav 105(3): 850-855.

GOUDIE AJ, SMITH JA, ROBERTSON A AND CAVANAGH C. 1999. Clozapine as a drug of dependence. Psychopharmacology (Berl) 142(4): 369-374. 
HIDA H, MOURI A, ANDO Y, MORI K, MAMIYA T, IWAMOTO K, OZAKI N, YAMADA K, NABESHIMA T AND NODA Y. 2014. Combination of neonatal PolyI:C and adolescent phencyclidine treatments is required to induce behavioral abnormalities with overexpression of GLAST in adult mice. Behav Brain Res 258: 34-42.

KIPARIZOSKA S AND IKUTA T. 2017. Disrupted Olfactory Integration in Schizophrenia: Functional Connectivity Study. Int J Neuropsychopharmacol 20(9): 740-746.

MILLER SS AND SPEAR NE. 2009. Olfactory learning in the rat immediately after birth: Unique salience of first odors. Dev Psychobiol 51(6): 488-504.

NIU H, HE X, ZHOU T, SHI X, ZHANG Q, ZHANG Z, QIAO Y, XU F AND HU M. 2015. Neural circuits containing olfactory neurons are involved in the prepulse inhibition of the startle reflex in rats. Front Behav Neurosci 9: 74.
PEARCE BD. 2001. Schizophrenia and viral infection during neurodevelopment: a focus on mechanisms. Mol Psychiatry 6: 634-646.

SCHNEIDER T AND PRZEWTOCKI R. 2005. Behavioral alterations in rats prenatally exposed to valproic acid: animal model of autism. Neuropsychopharmacol 30(1): 80-89.

WADEKAR M AND SYED S. 2010. Clozapine-withdrawal catatonia. Psychosomatics 51(4): 355-355.e2.

YEH AW, LEE JW, CHENG TC, WEN JK AND CHEN WH. 2004. Clozapine withdrawal catatonia associated with cholinergic and serotonergic rebound hyperactivity: a case report. Clin Neuropharmacol 27(5): 216-218.

ZUGNO AI ET AL. 2016. Effect of folic acid on oxidative stress and behavioral changes in the animal model of schizophrenia induced by ketamine. J Psychiatr Res 81 : 23-35. 